\title{
Molecular Iodine: A Powerful Catalyst for the Knoevenagel Condensation of Isatins with Malononitrile
}

\author{
Xiao Juan Yang, ${ }^{1}$ and Yong Sen Zhang ${ }^{2}$ \\ ${ }^{1}$ College of Chemistry and Chemical Engineering, Xinxiang University, Henan, Xinxiang 453003, China
}

${ }^{2}$ The Third Affiliated Hospital, Xinxiang Medical University, Henan, Xinxiang 45300, China

Correspondence should be addressed to Xiao Juan Yang; yangxiaojuan2005@126.com

Received 21 June 2012; Accepted 11 August 2012

Academic Editor: Xinyong Liu

Copyright ( $(2013$ X. J. Yang and Y. S. Zhang. This is an open access article distributed under the Creative Commons Attribution License, which permits unrestricted use, distribution, and reproduction in any medium, provided the original work is properly cited.

Molecular iodine has been used as an efficient catalyst for an improved and rapid condensation of isatins with malononitrile in excellent yields. The significant features of the iodine-catalyzed Knoevenagel condensation are operational simplicity, inexpensive reagents, high yield of products, and the use of nontoxic reagents.

\section{Introduction}

Isatin is a privileged lead molecule for designing potential bioactive agents, and its derivatives have been shown to possess a broad spectrum of bioactivity, as many of which have been assessed as anti-HIV [1], antiviral [2], antitumor [3], and anticonvulsants [4] agents. These interesting properties have prompted many efforts toward the synthesis and pharmacological screening of isatin derivatives. The most common methods for the synthesis of 2-(2-oxoindolin3 -ylidene)malononitriles are the condensation of isatins with malononitrile in the presence of a catalyst, such as piperidine acetate [5], DBU [6], $\mathrm{Al}_{2} \mathrm{O}_{3}$ [7], $\mathrm{N}\left(\mathrm{CH}_{2} \mathrm{CH}_{2} \mathrm{OH}\right)_{3}$ [8], chitosan [9]. Recently, MW irradiation [10] has also been applied to the condensation. However, most of these procedures have signicant drawbacks such as long reaction times, low yields, harsh reaction conditions, difficult workup, and use of environmentally toxic or expensive reagents or media. Thus, there is still a need for a simple and general protocol for the condensation of isatins with malononitrile.

Over the past few years, molecular iodine has emerged as powerful catalyst in various organic transformations [1114]. Owing to several advantages such as being inexpensive, nontoxic, and nature friendly, iodine affords the desired product in good to excellent range yields with high selectivity. As a part of our studies to explore the utility of iodinecatalyzed reactions $[15,16]$, we have described a novel and an efficient protocol for the Knoevenagel condensation of isatins with malononitrile using molecular iodine as the catalyst (Scheme 1).

\section{Experimental}

${ }^{1} \mathrm{H}$ NMR and ${ }^{13} \mathrm{C}$ NMR spectra were determined on Bruker AV-400 spectrometer (100 MHz for $\left.{ }^{13} \mathrm{C} \mathrm{NMR}\right)$ at room temperature using tetramethylsilane (TMS) as an internal standard (DMSO- $d_{6}$ solution); coupling constants $(J)$ were measured in $\mathrm{Hz}$; elemental analysis was performed by a Vario-III elemental analyzer; melting points were determined on a XT-4 binocular microscope and were uncorrected; commercially available reagents were used throughout without further purification unless otherwise stated.

2.1. General Procedure for the Preparation of 3 . A mixture of isatins $(1 \mathrm{mmol})$, malononitrile $(1 \mathrm{mmol})$, and $\mathrm{I}_{2}(0.1 \mathrm{mmol})$ in $\mathrm{EtOH}(10 \mathrm{~mL})$ was heated at $60^{\circ} \mathrm{C}$ for the appropriate time. The reaction was monitored by TLC. After completion, the mixture was treated with aqueous $\mathrm{Na}_{2} \mathrm{~S}_{2} \mathrm{O}_{3}$ solution extracted with ethyl acetate $(2 \times 10 \mathrm{~mL})$. The extract was dried over sodium sulfate, filtered and solvent was evaporated in vacuo. Products 3 were purified by recrystallizing from ethanol. 
<smiles>[R]c1ccc2c(c1)C(=O)C(=[OH+])N2[R]</smiles>

SCHEME 1

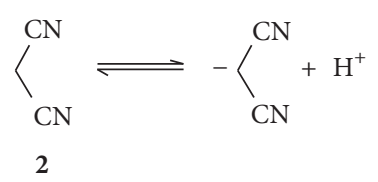<smiles>[R]c1ccc2c(c1)C(=C(C#N)C#N)C(=O)N2[R]</smiles>

SCHEME 2

2-(2-Oxoindolin-3-ylidene)malononitrile (3a): ${ }^{1} \mathrm{H} \quad \mathrm{NMR}$ $\left(\mathrm{DMSO}_{6}, 400 \mathrm{MHz}\right) \delta: 11.19(\mathrm{~s}, 1 \mathrm{H}), 7.87(\mathrm{~d}, 1 \mathrm{H}, J=$ $7.6 \mathrm{~Hz}), 7.56(\mathrm{t}, 1 \mathrm{H}, J=7.6 \mathrm{~Hz}), 7.12(\mathrm{t}, 1 \mathrm{H}, J=7.6 \mathrm{~Hz}), 6.93$ $(\mathrm{d}, 1 \mathrm{H}, J=8.0 \mathrm{~Hz}){ }^{13} \mathrm{C}$ NMR (DMSO- $\left.d_{6}, 100 \mathrm{MHz}\right) \delta: 164.1$, $151.0,146.9,126.2,123.3,119.0,113.4,112.1,111.9,81.0$; Anal. calcd for $\mathrm{C}_{11} \mathrm{H}_{5} \mathrm{~N}_{3} \mathrm{O}$ : C 67.69, $\mathrm{H}$ 2.58, N 21.53; found: C 67.52, H 2.66, N 21.58.

2-(5-Chloro-2-oxoindolin-3-ylidene)malononitrile

(3b): ${ }^{1} \mathrm{H}$ NMR (DMSO- $\left.d_{6}, 400 \mathrm{MHz}\right) \delta: 11.35$ (s, 1H), 7.75 $(\mathrm{s}, 1 \mathrm{H}), 7.62(\mathrm{~d}, 1 \mathrm{H}, J=8.4 \mathrm{~Hz}), 6.96(\mathrm{~d}, 1 \mathrm{H}, J=7.6 \mathrm{~Hz}) ;{ }^{13} \mathrm{C}$ NMR (DMSO- $\left.d_{6}, 100 \mathrm{MHz}\right) \delta: 163.8,150.0,145.6,137.4$, 126.9, 125.2, 120.3, 113.7, 113.1, 111.5, 82.7; Anal. calcd for $\mathrm{C}_{11} \mathrm{H}_{4} \mathrm{ClN}_{3} \mathrm{O}$ : C 57.54, $\mathrm{H}$ 1.76, N 18.30; found: C 57.46, H $1.78, \mathrm{~N} 18.42$.

2-(5-Bromo-2-oxoindolin-3-ylidene)malononitrile (3c): ${ }^{1} \mathrm{H}$ NMR (DMSO- $\left.d_{6}, 400 \mathrm{MHz}\right) \delta: 11.35$ (s, 1H), 7.90 $(\mathrm{s}, 1 \mathrm{H}), 7.74(\mathrm{~d}, 1 \mathrm{H}, J=8.4 \mathrm{~Hz}), 6.91(\mathrm{~d}, 1 \mathrm{H}, J=7.6 \mathrm{~Hz}) ;{ }^{13} \mathrm{C}$ NMR (DMSO- $\left.d_{6}, 100 \mathrm{MHz}\right) \delta: 163.7,149.9,145.9,140.1$, $128.0,120.9,114.4,114.1,113.1,111.6,82.6$; Anal. calcd for $\mathrm{C}_{11} \mathrm{H}_{4} \mathrm{BrN}_{3} \mathrm{O}$ : C 48.21, $\mathrm{H}$ 1.47, N 15.33; found: C 48.13, H $1.51, \mathrm{~N} 15.42$.

2-(5-Fluoro-2-oxoindolin-3-ylidene)malononitrile (3d): ${ }^{1} \mathrm{H}$ NMR (DMSO- $\left.d_{6}, 400 \mathrm{MHz}\right) \delta: 11.20(\mathrm{~s}, 1 \mathrm{H}), 7.55$ $(\mathrm{d}, 1 \mathrm{H}, J=6.0 \mathrm{~Hz}), 7.47(\mathrm{t}, 1 \mathrm{H}, J=8.8 \mathrm{~Hz}), 6.97-6.91$ (dd, $1 \mathrm{H}, J=4.0,8.4 \mathrm{~Hz}) ;{ }^{13} \mathrm{C} \mathrm{NMR}\left(\mathrm{DMSO}-d_{6}, 100 \mathrm{MHz}\right) \delta$ : $164.1,159.1,156.7,150.6,143.4,125.0,119.6,113.4,112.5$, 111.6, 82.7; Anal. calcd for $\mathrm{C}_{11} \mathrm{H}_{4} \mathrm{FN}_{3} \mathrm{O}$ : C 61.98, $\mathrm{H} 1.89, \mathrm{~N}$ 19.71; found: C 62.08, H 1.94, N 19.82.

2-(5-Nitro-2-oxoindolin-3-ylidene)malononitrile

(3e): ${ }^{1} \mathrm{H}$ NMR (DMSO- $\left.d_{6}, 400 \mathrm{MHz}\right) \delta: 11.91$ (s, 1H), 8.65 (s,
$1 \mathrm{H}), 8.44(\mathrm{~d}, 1 \mathrm{H}, J=8.0 \mathrm{~Hz}), 7.14(\mathrm{~d}, 1 \mathrm{H}, J=4.0,8.8 \mathrm{~Hz}) ;{ }^{13} \mathrm{C}$ NMR (DMSO- $\left.d_{6}, 100 \mathrm{MHz}\right) \delta: 164.4,151.6,149.7,142.8$, 133.1, 121.1, 119.2, 112.9, 112.3, 111.3, 83.9; Anal. calcd for $\mathrm{C}_{11} \mathrm{H}_{4} \mathrm{~N}_{4} \mathrm{O}$ : C 55.01, H 1.68, N 23.33; found: C 55.10, H 1.75, $\mathrm{N} 23.19$.

2-(1-Methyl-2-oxoindolin-3-ylidene)malononitrile (3f): ${ }^{1} \mathrm{H}$ NMR (DMSO- $\left.d_{6}, 400 \mathrm{MHz}\right) \delta: 7.90(\mathrm{~d}, 1 \mathrm{H}, J=$ $7.6 \mathrm{~Hz}), 7.65(\mathrm{t}, 1 \mathrm{H}, J=7.6 \mathrm{~Hz}), 7.21-7.14(\mathrm{~m}, 2 \mathrm{H}), 3.14(\mathrm{~m}$, $3 \mathrm{H}) ;{ }^{13} \mathrm{C}$ NMR (DMSO- $\left.d_{6}, 100 \mathrm{MHz}\right) \delta: 162.8,150.2,147.6$, 138.1, 125.9, 123.9, 118.4, 113.3, 111.8, 111.0, 81.6, 26.7; Anal. calcd for $\mathrm{C}_{12} \mathrm{H}_{7} \mathrm{~N}_{3} \mathrm{O}$ : C 68.89, $\mathrm{H}$ 3.37, $\mathrm{N}$ 20.09; found: C 68.92, H 3.29, N 20.15.

\section{Results and Discussion}

Exhaustive studies of the reaction conditions for the condensation of isatin with malononitrile in the presence of molecular iodine were conducted (Table 1). We examined several organic solvents, which are commercially available and used without further purification or drying. We found that a remarkable solvent effect existed in $10 \mathrm{~mol} \%$ iodinecatalyzed reaction at $60^{\circ} \mathrm{C}$. These results showed that EtOH was the most suitable solvent for this transformation among others, such as acetonitrile, toluene, THF, $\mathrm{CHCl}_{3}$, and $\mathrm{MeOH}$ (Table 1, entries 1-6). When the model reaction was carried out under room temperature, reduced yield was observed (Table 1, entry 7). Furthermore, the reaction was accelerated when the amount of catalyst was increased to $15 \mathrm{~mol} \%$, but the yield was not improved (Table 1, entry 8). When the reaction was catalyzed by $5 \mathrm{~mol} \%$ iodine, the reaction 
TABLE 1: Optimization studies of the condensation of isatin with malononitrile ${ }^{\mathrm{a}}$.

\begin{tabular}{|c|c|c|c|c|c|}
\hline Entry & $\mathrm{I}_{2}(\mathrm{~mol} \%)$ & Solvent & Temp. $\left({ }^{\circ} \mathrm{C}\right)$ & Time (min) & Yield $(\%)^{\mathrm{b}}$ \\
\hline 1 & 10 & $\mathrm{CH}_{3} \mathrm{CN}$ & 60 & 10 & 72 \\
\hline 2 & 10 & $\mathrm{PhMe}$ & 60 & 30 & 56 \\
\hline 3 & 10 & THF & 60 & 20 & 80 \\
\hline 4 & 10 & $\mathrm{CHCl}_{3}$ & 60 & 20 & 71 \\
\hline 5 & 10 & $\mathrm{MeOH}$ & 60 & 5 & 86 \\
\hline 6 & 10 & $\mathrm{EtOH}$ & 60 & 5 & 97 \\
\hline 7 & 10 & $\mathrm{EtOH}$ & 25 & 60 & 59 \\
\hline 8 & 15 & $\mathrm{EtOH}$ & 60 & 5 & 96 \\
\hline 9 & 5 & $\mathrm{EtOH}$ & 60 & 10 & 76 \\
\hline 10 & 0 & $\mathrm{EtOH}$ & 60 & 120 & 32 \\
\hline
\end{tabular}

Reaction conditions: isatin ( $1 \mathrm{mmol})$; malononitrile $(1 \mathrm{mmol})$.

${ }^{\mathrm{b}}$ Isolated yield.

TABLE 2: The Knoevenagel condensation of isatins with malononitrile catalyzed by $\mathrm{I}_{2}{ }^{\mathrm{a}}$.

\begin{tabular}{llccccc}
\hline Entry & $\mathrm{R}^{1}$ & $\mathrm{R}^{2}$ & Time $(\mathrm{min})$ & Product & Yield $(\%)^{\mathrm{b}}$ & m.p. $\left({ }^{\circ} \mathrm{C}\right)$ \\
\hline 1 & $\mathrm{H}$ & $\mathrm{H}$ & 5 & $\mathbf{3 a}$ & $\mathbf{3 b}$ & 97 \\
2 & $\mathrm{H}$ & $\mathrm{Cl}$ & 5 & $\mathbf{3 c}$ & 95 & $220-222$ \\
3 & $\mathrm{H}$ & $\mathrm{Br}$ & 5 & $\mathbf{3 d}$ & 99 & $223-225$ \\
4 & $\mathrm{H}$ & $\mathrm{F}$ & 3 & $\mathbf{3 e}$ & 98 & $230-231$ \\
5 & $\mathrm{H}$ & $\mathrm{NO}_{2}$ & $\mathrm{H}$ & 5 & $\mathbf{3 f}$ & \\
6 & $\mathrm{CH}_{3}$ & &
\end{tabular}

TABLE 3: Comparison of the effect of catalysts in synthesis of $\mathbf{3 a}$.

\begin{tabular}{|c|c|c|c|c|}
\hline Entry & Reagent and conditions & Time (min) & Yield $(\%)^{\mathrm{b}}$ & Reference \\
\hline 1 & Piperidine acetate, $\mathrm{CH}_{3} \mathrm{CN}$, reflux & 120 & 85 & {$[5]$} \\
\hline 2 & DBU, EtOH, reflux & 15 & 88 & {$[6]$} \\
\hline 3 & Piperidine, EtOH, reflux & 15 & 84 & [6] \\
\hline 4 & $\mathrm{Al}_{2} \mathrm{O}_{3}$, acetone, $\mathrm{MW}$ & 5 & 78 & [7] \\
\hline 5 & $\mathrm{I}_{2}, \mathrm{EtOH}, 60^{\circ} \mathrm{C}$ & 5 & 97 & The study \\
\hline
\end{tabular}

time was prolonged to $10 \mathrm{~min}$ and the desired product $\mathbf{3 a}$ was obtained with only $76 \%$ (Table 1 , entry 9). While a small number of product 3 a was obtained in the absence of molecular iodine (Table 1, entry 10). Thus, the most suitable reaction conditions for the formation of $\mathbf{3 a}$ were established (Table 1, entry 6).

Based on the above experimental results, different isatins are employed in the condensation of malononitrile. Both electron-rich (Table 2, entries 1-5) and electron-poor isatins (Table 3 , entries 6 ) could react with malononitrile smoothly to afford the corresponding 2-(2-oxoindolin-3ylidene)malononitriles in high yields.

The formation of products $\mathbf{3} \mathbf{a}-\mathbf{3} \mathbf{f}$ can be rationalized by standard Knoevenagel condensation of malononitrile $\mathbf{2}$ and isatins 1 in the presence of a catalytic amount of $\mathrm{I}_{2}$ (Scheme 2).

To illustrate the efficiency of the proposed method, Table 3 compares some of our results with some of those reported for relevant reagents in the literature, which demonstrates its significant superiority. Compared with some of the reported methods in Table 3, the present method has a short reaction time and good yield. In addition, molecular iodine is a stable, cost effective, and noncorrosive catalyst with high efficiency.

\section{Conclusion}

In summary, we have described a novel and an efficient protocol for the knoevenagel condensation of isatins with malononitrile using molecular iodine as the catalyst. The shorter reaction times, product yields, the easy procedure to carry out the reaction, and utilization of an inexpensive and readily available catalyst are the advantages of the present method.

\section{Acknowledgment}

The authors are pleased to acknowledge the financial support from Xinxiang University. 


\section{References}

[1] T. R. Bal, B. Anand, P. Yogeeswari, and D. Sriram, "Synthesis and evaluation of anti-HIV activity of isatin $\beta$-thiosemicarbazone derivatives," Bioorganic and Medicinal Chemistry Letters, vol. 15, no. 20, pp. 4451-4455, 2005.

[2] T. Jiang, K. L. Kuhen, K. Wolff et al., "Design, synthesis, and biological evaluations of novel oxindoles as HIV-1 nonnucleoside reverse transcriptase inhibitors. Part 2," Bioorganic and Medicinal Chemistry Letters, vol. 16, no. 8, pp. 2109-2112, 2006.

[3] R. Tripathy, A. Reiboldt, P. A. Messina et al., "Structure-guided identification of novel VEGFR-2 kinase inhibitors via solution phase parallel synthesis," Bioorganic and Medicinal Chemistry Letters, vol. 16, no. 8, pp. 2158-2162, 2006.

[4] M. Verma, S. N. Pandeya, K. N. Singh, and J. P. Stables, "Anticonvulsant activity of Schiff bases of isatin derivatives," Acta Pharmaceutica, vol. 54, no. 1, pp. 49-56, 2004.

[5] Y. S. Kayukov, O. V. Kayukova, E. S. Kalyagina et al., "Reactions of $2^{\prime}$-oxo- $1^{\prime}, 2^{\prime}$-dihydrospiro[cyclopropane- $1,3^{\prime}$-indole]2,2,3,3-tetracarbonitriles with nucleophiles," Russian Journal of Organic Chemistry, vol. 47, no. 3, pp. 392-401, 2011.

[6] I. A. Abdelhamid, M. H. Mohamed, A. M. Abdelmoniem, and S. A. S. Ghozlan, "DBU-Catalyzed, facile and efficient method for synthesis of spirocyclic 2-oxindole derivatives with incorporated 6-amino- $4 H$-pyridazines and fused derivatives via [3+3] atom combination," Tetrahedron, vol. 65, no. 48, pp. 10069-10073, 2009.

[7] A. Dandia, H. Taneja, R. Gupta, and S. Paul, "An efficient procedure for the synthesis of spiro $\left[3 H\right.$-indole- $3,4^{\prime}\left(1^{\prime} H\right)$ pyrano $[2,3-c]$ pyrrole $]-5^{\prime}$-carbonitriles using solid inorganic supports and microwave activation," Synthetic Communications, vol. 29, no. 13, pp. 2323-2335, 1999.

[8] R. G. Redkin, L. A. Shemchuk, V. P. Chernykh, O. V. Shishkin, and S. V. Shishkina, "Synthesis and molecular structure of spirocyclic 2-oxindole derivatives of 2-amino- $4 H$-pyran condensed with the pyrazolic nucleus," Tetrahedron, vol. 63, no. 46, pp. 11444-11450, 2007.

[9] I. A. Abdelhamid, "Synthesis of novel spiro cyclic 2-oxindole derivatives of 6-amino- $4 \mathrm{H}$-pyridazine via [3+3] atom combination utilizing chitosan as a catalyst," Synlett, no. 4, pp. 625-627, 2009.

[10] A. Dandia, K. Arya, M. Sati, and R. Sharma, "Facile microwaveassisted one-pot solid phase synthesis of spiro[3H-indole- $3,4^{\prime}$ pyrazolo[3,4-b] pyridines]," Heterocyclic Communications, vol. 9, no. 4, pp. 415-420, 2003.

[11] M. Kidwai, P. Mothsra, V. Bansal et al., "One-pot synthesis of highly substituted imidazoles using molecular iodine: a versatile catalyst," Journal of Molecular Catalysis A, vol. 265, no. 1-2, pp. 177-182, 2007.

[12] M. Kidwai, V. Bansal, and P. Mothsra, "Molecular iodine: a highly efficient catalyst for the synthesis of 7-arylbenzopyran$\mathrm{o}[1,3]$ diazepines in non-protic solvents," Journal of Molecular Catalysis A, vol. 266, no. 1-2, pp. 43-46, 2007.

[13] M. Kidwai and P. Mothsra, "A one-pot synthesis of 1,2,4,5tetraarylimidazoles using molecular iodine as an efficient catalyst," Tetrahedron Letters, vol. 47, no. 29, pp. 5029-5031, 2006.

[14] S. Ko, M. N. V. Sastry, C. Lin, and C. F. Yao, "Molecular iodinecatalyzed one-pot synthesis of 4-substituted-1,4- dihydropyridine derivatives via Hantzsch reaction," Tetrahedron Letters, vol. 46, no. 34, pp. 5771-5774, 2005.
[15] L. Wu, B. Niu, W. Li, and F. Yan, "Molecular iodine: a versatile catalyst for the synthesis of 2-aryl-2,3-dihydroquinolin-4(1H)ones," Bulletin of the Korean Chemical Society, vol. 30, no. 11, pp. 2777-2778, 2009.

[16] X. Wang, G. Lu, W. Ma, and L. Wu, "Molecular iodine: a versatile catalyst for the synthesis of $2 \mathrm{H}$-indazolo[2,1-b]phthalazine1,6,11(13H)-trione derivatives in ethanol," E-Journal of Chemistry, vol. 8, no. 3, pp. 1000-1005, 2011. 

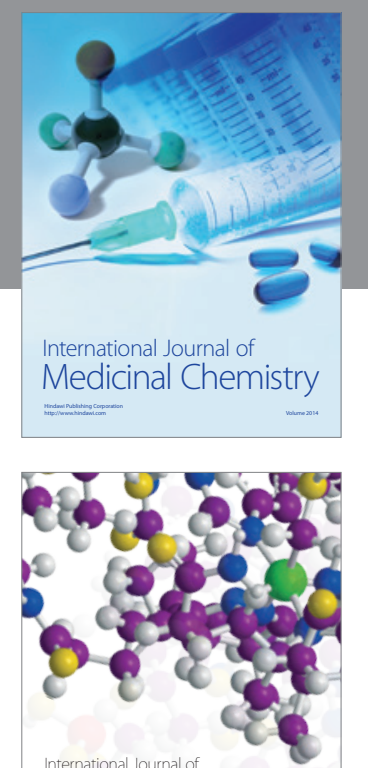

\section{Carbohydrate} Chemistry

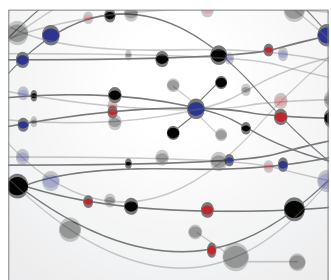

The Scientific World Journal
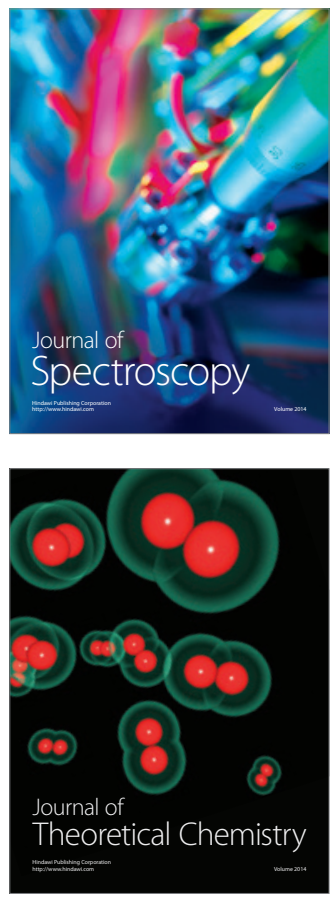
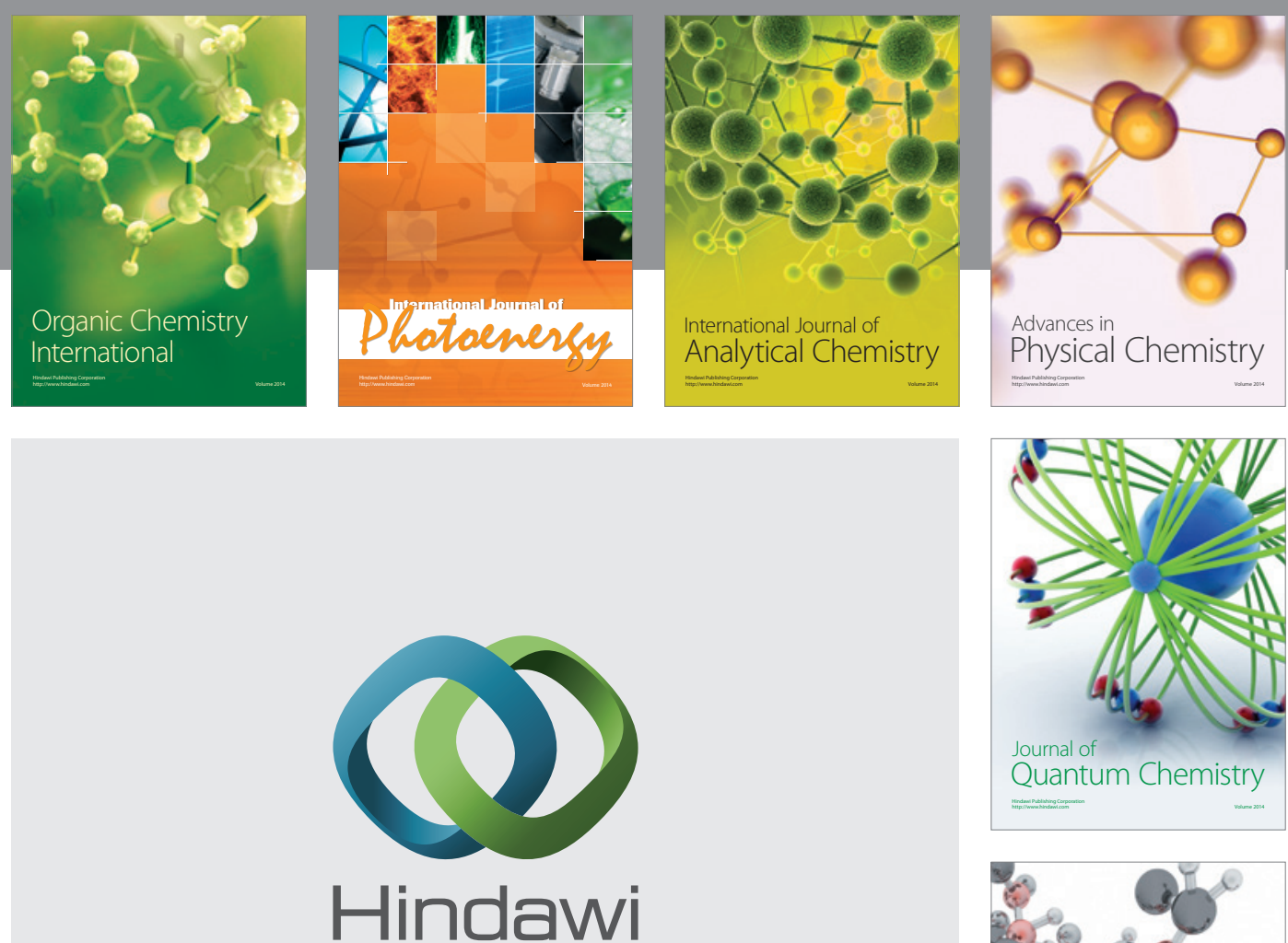

Submit your manuscripts at

http://www.hindawi.com

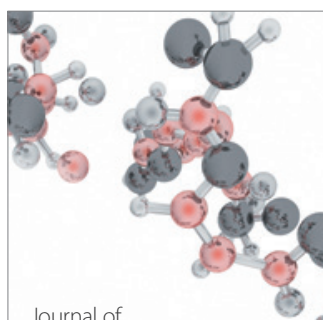

Analytical Methods

in Chemistry

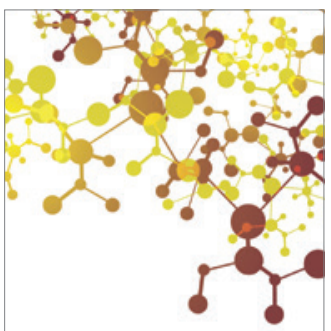

Journal of

Applied Chemistry

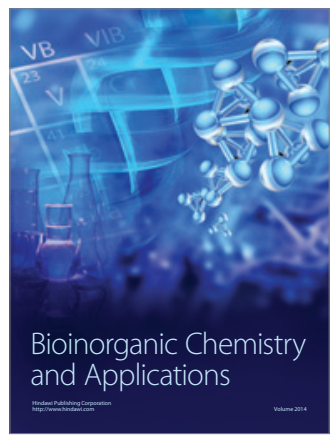

Inorganic Chemistry
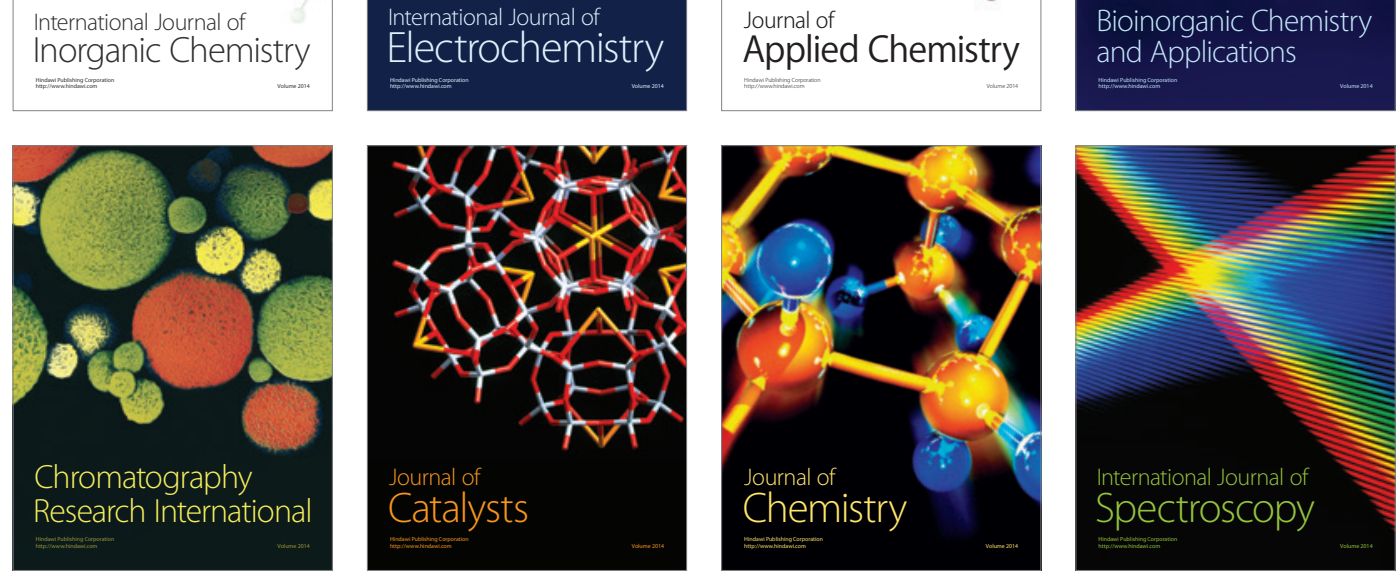